\title{
The impact of radiotherapy in the treatment of desmoid tumours. An international survey of I I 0 patients. A study of the Rare Cancer Network
}

\author{
Brigitta G Baumert*1,2, Martin O Spahr ${ }^{1}$, Arthur Von Hochstetter ${ }^{3}$, \\ Sylvie Beauvois ${ }^{4,25}$, Christine Landmann ${ }^{5}$, Katrin Fridrich ${ }^{6,24}$, Salvador Villà7, \\ Michael J Kirschner, 22, Guy Storme ${ }^{9}$, Peter Thum¹0, Hans K Streuli11, \\ Norbert Lombriser ${ }^{12}$, Robert Maurer ${ }^{13}$, Gerhard Ries ${ }^{14}$, Ernst-Arnold Bleher ${ }^{15}$, \\ Alfred Willi16, Juerg Allemann17, Ulrich Buehler ${ }^{18}$, Hugo Blessing 19,26, \\ Urs M Luetolf1, J Bernard Davis ${ }^{1}$, Burkhardt Seifert ${ }^{20}$ and \\ Manfred Infanger 21,23
}

Address: ${ }^{1}$ Radiation Oncology, University Hospital Zurich, Switzerland, ${ }^{2}$ Dept of Radiation Oncology (MAASTRO), GROW, University Hospital Maastricht, The Netherlands, ${ }^{3}$ Dept. of Pathology, University Hospital Zurich, Switzerland, ${ }^{4}$ Dept. de Radio-Oncologie, Centre des Tumeurs de l'Université Libre de Bruxelles, Belgium, ${ }^{5}$ Radiation Oncology, University Hospital Basel, Switzerland, 6 Institute for Pathology, University Hospital Basel, Switzerland, ${ }^{7}$ Radiation Oncology, Institut Català d'Oncologia, Barcelona, Spain, ${ }^{8} \mathrm{Klinik}$ und Poliklinik fuer Strahlentherapie, Erlangen,

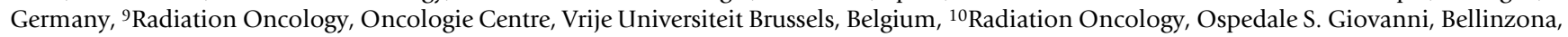
Switzerland, ${ }^{11}$ Chirurgische Klinik, Kantonsspital Aarau, Switzerland, ${ }^{12}$ Radio-Onkologie, Stadtspital Triemli, Zurich, Switzerland, ${ }^{13}$ Dept. of Pathology, Stadtspital Triemli, Zurich, Switzerland, ${ }^{14}$ Radiation Oncology, Kantonsspital St. Gallen, Switzerland, ${ }^{15}$ Dept. of Radiation Oncology, University Hospital Bern, Switzerland, ${ }^{16}$ Radiation Oncology, Kantonsspital Chur, Switzerland, ${ }^{17}$ Dept. of Pathology, Kantonsspital Chur, Switzerland, ${ }^{18}$ Chirurgische Klinik, Spital Schiers, Switzerland, ${ }^{19}$ Chirurgische Klinik, Kantonsspital Glarus, Switzerland, ${ }^{20}$ Dept. of Biostatistics, University Zurich, Switzerland, ${ }^{21}$ Dept. of Hand-Plastic-and Reconstructive Surgery, University Hospital Zurich, Switzerland, ${ }^{22}$ Praxis fuer Strahlentherapie, Solingen, Germany, ${ }^{23}$ Dept. of Hand, Plastic and Reconstructive Surgery, Charite, University Medicine Berlin, Germany, ${ }^{24}$ Pathology Clinics, Rikshospitalet-Radiumhospitalet Medical Center, Oslo, Norway, ${ }^{25}$ Service de Radiothérapie, Clinique Saint Jean, Brussels, Belgium and ${ }^{26}$ Deceased 1999

Email: Brigitta G Baumert* - brigitta.baumert@maastro.nl; Martin O Spahr - martin@spahrquartett.ch; Arthur Von Hochstetter - pie@pathol.unizh.ch; Sylvie Beauvois - sbeauvois@clstjean.be; Christine Landmann - clandmann@uhbs.ch; Katrin Fridrich - Katrin.Fridrich@rikshospitalet.no; Salvador Villà - svilla@iconcologia.net; Michael J Kirschner - michael-kirschner@t-online.de; Guy Storme - guy.storme@az.vub.ac.be; PeterThum - peter.thum@ksl.ch; Hans K Streuli - brigitta.baumert@maastro.nl;

Norbert Lombriser - norbert.lombriser@triemli.stzh.ch; Robert Maurer - robert.maurer@triemli.stzh.ch; Gerhard Ries - gerhard.ries@kssg.ch; Ernst-Arnold Bleher - eableher@hispeed.ch; Alfred Willi - brigitta.baumert@maastro.nl; Juerg Allemann - jallemann@spin.ch; Ulrich Buehler - spital.schiers@spin.ch; Hugo Blessing - brigitta.baumert@maastro.nl; Urs M Luetolf - urs.luetolf@usz.ch; J Bernard Davis - bernard.davis@usz.ch; Burkhardt Seifert - seifert@ifspm.unizh.ch; Manfred Infanger - manfred.infanger@charite.de

* Corresponding author

\section{Published: 7 March 2007}

Radiation Oncology 2007, 2:12 doi:10.1/86/1748-7/7X-2-12

This article is available from: http://www.ro-journal.com/content/2/I//2

(c) 2007 Baumert et al; licensee BioMed Central Ltd.

This is an Open Access article distributed under the terms of the Creative Commons Attribution License (http://creativecommons.org/licenses/by/2.0), which permits unrestricted use, distribution, and reproduction in any medium, provided the original work is properly cited.
Received: 4 December 2006

Accepted: 7 March 2007

\footnotetext{
Abstract

Purpose: A multi-centre study to assess the value of combined surgical resection and radiotherapy for the treatment of desmoid tumours.

Patients and methods: One hundred and ten patients from several European countries qualified for this study. Pathology slides of all patients were reviewed by an independent pathologist. Sixty-
} 
eight patients received post-operative radiotherapy and 42 surgery only. Median follow-up was 6 years (I to 44). The progression-free survival time (PFS) and prognostic factors were analysed.

Results: The combined treatment with radiotherapy showed a significantly longer progressionfree survival than surgical resection alone ( $p$ smaller than $0.00 \mathrm{I}$ ). Extremities could be preserved in all patients treated with combined surgery and radiotherapy for tumours located in the limb, whereas amputation was necessary for $23 \%$ of patients treated with surgery alone. A comparison of PFS for tumour locations proved the abdominal wall to be a positive prognostic factor and a localization in the extremities to be a negative prognostic factor. Additional irradiation, a fraction size larger than or equal to $2 \mathrm{~Gy}$ and a total dose larger than $50 \mathrm{~Gy}$ to the tumour were found to be positive prognostic factors with a significantly lower risk for a recurrence in the univariate analysis. This analysis revealed radiotherapy at recurrence as a significantly worse prognostic factor compared with adjuvant radiotherapy. The addition of radiotherapy to the treatment concept was a positive prognostic factor in the multivariate analysis.

Conclusion: Postoperative radiotherapy significantly improved the PFS compared to surgery alone. Therefore it should always be considered after a non-radical tumour resection and should be given preferably in an adjuvant setting. It is effective in limb preservation and for preserving the function of joints in situations where surgery alone would result in deficits, which is especially important in young patients.

\section{Background}

Desmoid tumours are uncommon benign soft tissue neoplasms. Their incidence is reported to be $2-4 / 1.000 .000$ inhabitants in Finland $[1,2]$ or $3 \%$ of all soft tissue tumours [3]. Aggressive fibromatoses or desmoid tumours are fibroblastic lesions with aggressive, infiltrative and destructive growth, which frequently recur if not widely resected [4]. Depending on the three major anatomic locations in which they arise, they are classified as: extraabdominal fibromatosis, abdominal desmoid, occurring typically in women during or following pregnancy; and intra-abdominal fibromatosis, either a pelvic or mesenteric location. While most cases are sporadic, some are associated with familial adenomatous polyposis (FAP, Gardner's Syndrome) and these are most often intraabdominal [5]. There are also cases of familial desmoid tumours at multiple sites, often involving one extremity, in patients without FAP. In both FAP and familial nonFAP tumours, mutations of the adenomatous polyposis coli (APC) gene on the long arm of chromosome 5 have been incriminated. The resultant loss of ability to degrade beta-catenin and elevated beta-catenin levels promotes fibroblastic proliferation [6]. In all settings and locations these fibroblastic proliferations are similar: variably cellular, often hypocellular ill-defined fascicles of fibroblasts and myofibroblasts lacking nuclear pleomorphism and showing little mitotic activity [7].

As fibromatoses do not metastasise, surgical radicality is often compromised when weighed against function preservation. It is the ill-defined margins of infiltration along septal planes that lead to recurrences. This necessitates mutilating operations, which may be avoided by adding radiotherapy to the treatment regimen. Relapse rates at 5 years after radiotherapy are reported as 33\% [8,9]. Recent literature shows growing evidence that the addition of radiotherapy results in better local control than surgery alone independent of resection margin status $[10,11]$. This might support the hypothesis that with a combined treatment only modest surgical interventions may be needed, thus avoiding disfigurement. Additionally, radiotherapy alone may serve as a primary therapy and result in minor or no deficits for those patients whose tumours are un-resectable. Data for this study were obtained from European centres which are members of the "Rare Cancer Network" [12]. This study aims to contribute to an assessment of the therapeutic value of radiotherapy in the multimodal treatment of desmoid tumours.

\section{Patients and methods \\ Patient selection}

Departments of Surgery and Radiation Oncology of 14 centres within the Rare Cancer Network from 4 European countries participated in this study (Table 1). Departments of Pathology provided databases, but treatment data were collected from Surgery and Radiation Oncology only. In large Swiss centres, patients were discussed and treatment decisions taken centrally, for some patients part of treatment was done in smaller centres. A questionnaire concerning prognostic factors, postulated aetiology, treatment parameters, outcome, side-effects and follow-up was sent to the participating centres. The records of 140 patients were reported. All cases were histologically reviewed by an independent reference pathologist of the Pathology Department, University Hospital Zurich. After a histological review, only 110 of 140 patients were found 
to be eligible. They were treated between 1956 and 1997 and followed until 2001. Thirty patients were excluded because of a different diagnosis (e.g. malignant fibromyosarcoma, Dupuytren, juvenile fibromatosis) or insufficient information available for pathologic review. Data were reported and analyzed throughout the whole study anonymously using a coding system based on consecutive numbers per patient and per centre.

\section{General}

The median follow-up period was 6 years (range $1-44$ years), for 4 patients data were insufficient for follow-up. Thus, 106 patients were evaluable for the survival analysis and 110 patients for descriptive statistics. One patient had a bifocal disease (left and right arm), where one tumour was treated with surgery alone and the other with surgery and post-operative radiotherapy. Seventy-eight patients were female, 32 male. Fifty-nine percent of all recurrences appeared during the first 2 years and $82 \%$ within 5 years of treatment. One patient died of intercurrent disease.

Sixty-eight patients were treated with surgery and postoperative radiotherapy $(\mathrm{Sx}+\mathrm{RT}), 42$ with surgical resection alone $(\mathrm{Sx})$. An overview of the patients' characteristics and distribution between both groups is given in Table 2 . The two treatment groups were statistically comparable in terms of age, gender, resection margins and aetiological factors. The resection margin status at first operation shows a significant difference in frequencies, mainly for $\mathrm{R} 1$ resection, however, numbers are small. For further statistical evaluation, margins of R0 and R1 are grouped together as radical resection, and R2, R3 and unknown as non-radical resection (Radical: $59 \%$ for the $\mathrm{Sx}+\mathrm{RT}$ group, $55 \%$ for $\mathrm{Sx}$, non-radical: $41 \%$ for $\mathrm{Sx}+\mathrm{RT}, 44 \%$ for $\mathrm{Sx})$. The number of re-operations was higher in the group which

Table I: Participating institutes

\begin{tabular}{lcc}
\hline Dept*. of Radiation Oncology & Country & No. patients \\
\hline Institute J. Bordet Brussels & Belgium & 22 \\
University Hospital Basel & Switzerland & 21 \\
University Hospital Zurich & Switzerland & I5 \\
Catalan Institute of Oncology Barcelona & Spain & I5 \\
Ospedale San Giovanni Bellinzona & Switzerland & 4 \\
University Hospital VUB Brussels & Belgium & 4 \\
University Hospital Erlangen & Germany & 5 \\
Stadtspital Triemli Zurich & Switzerland & 3 \\
Kantonsspital St. Gallen & Switzerland & 3 \\
University Hospital Berne & Switzerland & 2 \\
Kantonsspital Chur & Switzerland & I \\
& & \\
Dept. of Surgery & & 7 \\
Kantonsspital Chur, Glarus and Schiers & Switzerland & 5 \\
Kantonsspital Aarau & Switzerland & 5 \\
Stadtspital Zurich & Switzerland & 3 \\
\hline
\end{tabular}

Abbreviation: * Dept.: departments received postoperative radiotherapy $(\mathrm{p}<0.0001)$. The frequencies of tumour localization were differently distributed within both groups, mainly for tumour localization of abdominal wall and extremities. Tumours of the trunk include the following localizations: 4 tumours in the breast, 5 intra-thoracic, 12 intra-peritoneal and 1 retroperitoneal tumour. The median age was 33 years (range 1 - 78). The majority of patients were between $21-40$ years old at the time of the first treatment. Patients were regularly followed-up, clinically and by imaging according to each department's scheme. Imaging was by MRI scans since its general availability.

\section{Treatment}

All patients had surgery and none had radiotherapy alone. Baseline operations were reported between 1956 and 1996. Radiation was given between 1964 and 1997. Five patients had a wide biopsy and were classified as having macroscopic residual margin. Surgical margins were defined as follows: wide excision with a margin $>1 \mathrm{~cm}$ (R0), margin < $1 \mathrm{~cm}$ (R1), microscopic residual tumour (R2) and macroscopic residual tumour (R3) (Table 3). The indications for radiotherapy were primary radiotherapy after biopsy or wide biopsy only, postoperative adjuvant radiotherapy or in case of recurrence. Radiotherapy techniques and dose specifications differed over the time span of this study and between participating centres. In order to have comparable therapeutic nominal doses, all doses were recalculated and reported according to ICRU recommendations [13]. Two cases could not be considered for dose recalculation, because specifications about radiotherapy doses were not available. In 62 cases the radiotherapy technique used was external beam radiotherapy with photons and/or electrons from a linear accelerator or Cobalt unit. In 4 cases brachytherapy was used as a boost and in 3 cases orthovoltage X-rays were used. For two patients a split course technique was used. Fraction size ranged from $1.5 \mathrm{~Gy}$ to $3 \mathrm{~Gy}$ (median $2.28 \mathrm{~Gy}$ ). The median total radiation dose was $59.4 \mathrm{~Gy}$ in 29 fractions (Range 3.4 Gy-73.7 Gy). Eight patients received 50 Gy or less. For details see Table 2.

\section{Statistical analysis}

Data were analysed using the SPSS (version 13 for Mac OS $\mathrm{X}$, SPSS Inc. IL) and the Stata software packages (Release 8.2, Stata Corp.). Groups were compared using Fisher's Exact test and the Mann-Whitney test when appropriate. The progression-free survival (PFS) was calculated beginning with the date of first surgery until recurrence or last follow-up. The overall progression-free survival was analysed using Kaplan-Meier curves and the log-rank test. For this analysis there is one endpoint per patient, i.e. the outcome at the last follow-up after all therapeutic events independent of the order or indication of treatments (i.e. several operations before radiotherapy, or the number of 
Table 2: Patients' characteristics

\begin{tabular}{|c|c|c|c|c|}
\hline Factor & Total No. & Surgery and radiotherapy & Surgery alone & P-value \\
\hline Follow-up (yrs) & $0(1-44)$ & $7.8(0.6-44.3)$ & $3.1(0.1-24.9)$ & $<0.0001$ \\
\hline Age (yrs) & $33(1-78)$ & $33(1-78)$ & $32(1-65)$ & n.s.* \\
\hline \multicolumn{5}{|l|}{ Gender } \\
\hline Male & $32(29 \%)$ & $20(29 \%)$ & $12(29 \%)$ & n.s. \\
\hline Female & 78 (7I\%) & 48 (7।\%) & $30(7 \mid \%)$ & \\
\hline Tumour localization & & & & 0.003 \\
\hline Abdominal wall, testicular sheath & $25(23 \%)$ & $10(15 \%)$ & $15(36 \%)$ & \\
\hline Head and neck & $7(6 \%)$ & $6(9 \%)$ & I (2\%) & \\
\hline Extremities, shoulder girdle, hip & $56(51 \%)$ & $43(63 \%)$ & $13(31 \%)$ & \\
\hline Trunk, pelvis, breast & $22(20 \%)$ & $9(13 \%)$ & $13(31 \%)$ & \\
\hline Resection margin & & & & 0.004 \\
\hline Ro & $16(14 \%)$ & $4(6 \%)$ & $12(29 \%)$ & \\
\hline RI & $47(43 \%)$ & $36(53 \%)$ & II (26\%) & \\
\hline $\mathrm{R} 2$ & $20(18 \%)$ & $14(2 \mid \%)$ & $6(14 \%)$ & \\
\hline R3 & $13(12 \%)$ & $7(10 \%)$ & $6(14 \%)$ & \\
\hline Unknown & $14(13 \%)$ & $7(10 \%)$ & $7(17 \%)$ & \\
\hline Number re-operations & $2.3 / 2.0(1-12)$ & $2.65 / 2.0(I-7)$ & $1.74 / 1.0(1-12)$ & $<0.0001$ \\
\hline Radiotherapy dose & $56.5 / 59.4$ & $57.4 / 59.4$ & - & - \\
\hline$>50 \mathrm{~Gy}$ & $58(53 \%)$ & $58(85 \%)$ & - & \\
\hline$<=50 \mathrm{~Gy}$ & $8(8 \%)$ & $8(12 \%)$ & - & \\
\hline No dose, unknown & $44(39 \%)$ & $2(3 \%)$ & - & \\
\hline Fraction size & $2.28 / 2.0$ & $2.29 / 2.00$ & - & - \\
\hline$>=2 \mathrm{~Gy}$ & $40(36 \%)$ & 40 (59\%) & - & \\
\hline$<2 \mathrm{~Gy}$ & $15(14 \%)$ & $15(22 \%)$ & - & \\
\hline No dose, unknown & 55 (50\%) & 13 (19\%) & - & \\
\hline \multicolumn{5}{|l|}{ Indication radiotherapy } \\
\hline Adjuvant & $24(22 \%)$ & $24(35 \%)$ & - & - \\
\hline At recurrence & 39 (35\%) & $39(57 \%)$ & - & \\
\hline Primary & $5(4 \%)$ & $5(7 \%)$ & - & \\
\hline \multicolumn{5}{|l|}{ Etiological factor } \\
\hline Yes & $44(40 \%)$ & $29(43 \%)$ & $15(36 \%)$ & n.s. \\
\hline No & $66(60 \%)$ & $39(57 \%)$ & 27 (64\%) & \\
\hline
\end{tabular}

Numbers present: median (range), mean/median (range), no. (\%).

Abbreviation: $*_{\text {n.s.: not significant }}$

Table 3: Recurrence rates after first operation according to resection margin status

\begin{tabular}{cccc}
\hline Resection margin & \multicolumn{1}{c}{ Recurrence rate No. patients (\%) } & Surgery and radiotherapy No. (\%) & Surgery alone No. (\%) \\
R0 & $5 / 16(31)$ & $2 / 4(50)$ & $3 / 12(25)$ \\
RI & $30 / 47(64)$ & $27 / 36(75)$ & $3 / 11(27)$ \\
R2 & $11 / 20(55)$ & $9 / 14(64)$ & $2 / 6(33)$ \\
R3 & $7 / 13(54)$ & $5 / 7(71)$ & $2 / 6(33)$ \\
RX & $7 / 14(50)$ & $5 / 7(71)$ & $2 / 7(29)$ \\
\hline
\end{tabular}

R0, wide excision; RI, margin < I cm; R2, microscopic residual tumour; R3, macroscopic residual tumour; RX, unknown. 
resections before and after radiotherapy etc). Progressionfree survival between multiple events (i.e. multiple recurrences and treatments in one patient) was analyzed using a Cox Regression Model with shared frailty. This way, the effect of different radiotherapy treatments during the course of the disease due to recurrences within the same patient can be analyzed taking into account the different aggressiveness of tumours and the correlation between recurrences within the same patient. In a Cox Regression Model with shared frailty (Stata, procedure stcox), frailties are gamma-distributed latent random effects that enter multiplicatively in the hazard. Those frailties are shared by (and thus are constant for) all events within the same patient. The variance of frailties is estimated by iterative maximum profile log-likelihood. Univariate and multivariate analyses of multiple events were performed using a Cox Regression Model with shared frailty to determine the possible prognostic factors of gender, age, aetiology, resection margin, tumour localization, radiation therapy, radiotherapy indications, total radiotherapy dose and fraction size. A result was significant if $\mathrm{p}<0.05$.

\section{Results}

\section{Descriptive analysis - Surgery}

As follow-up data for 4 patients were missing, 38 patients were available for analysis. The number and percentages of recurrences after the first operation are shown in Table 3 . The recurrence rate after the first surgical resection was $32 \%(12 / 38)$. Recurrence rates are lower for patients treated with surgery alone after the first resection (selection bias in favour of the surgery alone group). The lowest recurrence rate $(31 \%)$ is found after wide radical resection (R0). Fourteen out of 42 patients had between 1 and 12 re-operations (mean/median 1.74/1.0). For 56 patients with a tumour located in the extremities, 13 were treated with surgery alone. Amputation was necessary for 3 of them $(23 \%)$. One patient was disease-free after amputation, the remaining two patients relapsed and were treated with radiotherapy and were progression-free thereafter.

\section{Descriptive analysis - Radiotherapy}

Of the 68 patients in the RT group, 22 patients were irradiated after the first operation, 25 after the first recurrence and 21 after the second or further recurrences. Seventeen of the 68 patients $(25 \%)$ had local failures after post-operative irradiation with a median dose of 55.6 Gy (Range: $3.4-68 \mathrm{~Gy}$ ). Recurrences were seen at the field borders in 7 cases and within the field in 10 cases. In 11 of those 17 cases $(65 \%)$, recurrences were seen in areas where the dose was less than $50 \mathrm{~Gy}$. Of those 17 patients, 11 were reoperated after irradiation, the tumour recurring in 3 patients and persisting in one thereafter. Seven patients were re-irradiated with a median dose of 50 Gy (Range: 40 - 65 Gy), 3 of them recurred. In all 43 patients treated with post-operative radiotherapy for a tumour located in the limbs, the extremities could be preserved.

\section{Descriptive analysis - Tamoxifen}

Ten patients received an additional therapy with Tamoxifen: one patient after surgery, 4 patients for recurrence after irradiation, and 5 patients in combination with radiotherapy. Only one patient responded to Tamoxifen therapy. In 3 cases the tumour progressed under Tamoxifen therapy.

\section{Descriptive analysis - Aetiology}

Aetiological factors were reported for 44 cases. These were the site of a previous trauma or an operation in 18 cases, pregnancy in 17 cases and the Gardner-Syndrome in 9 cases. No significant difference in the PFS between patients with and without known aetiological factors was found (Table 4).

\section{Descriptive analysis - Toxicity}

Side effects of treatment were reported for 76 patients only. Toxicity reported after surgery was as follows: no side effects (8 patients), pain (4), malabsorption syndrome (4), stiffening of joints (3), paresis (2), paraesthesia (1), fistula (1), ileus (1), lymph oedema (1), phantom pain (1), skin erythema (1), scar herniation (1), screw migration (1). Late side effects after combined surgery and radiotherapy were: stiffening of joints (22), hyper-pigmentation (11), paraesthesia (9), pain (6), paresis (6), skin ulceration (2), colon irritabile (1), ileus (1), scoliosis (1), scar-herniation (1), xerostomy (1). No radiotherapyinduced sarcoma was reported.

\section{Survival analysis - Overall outcome}

The overall outcome for the whole group after all therapeutic interventions (independently of number and order of treatments) showed progressive disease (7 patients), stable disease ( 9 patients) and no evidence of disease ( 94 patients). Figure 1 shows the overall outcome as endpoint with the tumour status as reported at the last follow-up. For patients treated with surgery and radiotherapy the PFS was $95 \%$ and $93 \%$ at 5 and 10 years respectively. For patients treated with surgery alone the PFS was $84 \%$ and $62 \%$ at 5 and 10 years, respectively. The difference was statistically significant $(p=0.0028)$. In order to answer the question of the role of radiotherapy in a combined treatment setting, an event-related analysis was performed. This analysis, which uses the Cox Regression Model with shared frailty (see statistics section above), looked at a presumed additional tumour-related risk factor per patient resulting in multiple recurrences after surgery alone or after combined treatment. This resulted in a different time-relationship between surgery and radiotherapy for each patient. The "shared frailty" model takes this into account. The progression-free survival was significantly 
Table 4: Analysis of prognostic factors for progression-free survival (Cox proportional hazard with frailty)

\begin{tabular}{|c|c|c|c|c|c|c|}
\hline \multirow[t]{2}{*}{ Factor } & \multicolumn{3}{|c|}{ Univariate } & \multicolumn{3}{|c|}{ Multivariate* } \\
\hline & $\mathrm{HR}$ & $(95 \% \mathrm{Cl})$ & $\mathrm{P}$-value & $\mathrm{HR}$ & $(95 \% \mathrm{Cl})$ & $\mathrm{p}$-value \\
\hline Radiation therapy & 0.19 & $(0 .|I-0.3|)$ & $<0.001$ & $0.21^{*}$ & $(0.13-0.34)$ & $<0.001$ \\
\hline Radiotherapy dose (>50 Gy) & 0.60 & $(0.38-0.97)$ & 0.028 & & & \\
\hline Fraction size ( $\geq 2$ Gy) & 0.59 & $(0.37-0.95)$ & 0.036 & & & \\
\hline Resection margins* & 1.07 & $(0.72-1.58)$ & n.s. & & & \\
\hline \multicolumn{7}{|l|}{ Indication radiotherapy } \\
\hline Adjuvant radiotherapy & 0.42 & $(0.25-0.72)$ & 0.002 & & & \\
\hline Radiotherapy at recurrence & 2.69 & $(I .63-4.4 I)$ & $<0.001$ & & & \\
\hline Primary radiotherapy & 0.36 & $(0.11-1.15)$ & n. s. & & & \\
\hline \multicolumn{7}{|l|}{ Tumour localization } \\
\hline Head-neck & 0.96 & $(0.46-2.00)$ & n.s. & & & \\
\hline Trunk & 0.67 & $(0.37-1.18)$ & n.s. & & & \\
\hline Abdominal wall & 0.42 & $(0.21-0.85)$ & 0.017 & $0.28^{*}$ & $(0.15-0.53)$ & $<0.001$ \\
\hline Extremities* & 2.5 & $(1.68-3.62)$ & $<0.001$ & & & \\
\hline Potential etiological factors & 0.90 & $(0.61-1.32)$ & n.s. & & & \\
\hline Gender (male) & 0.95 & $(0.62-1.45)$ & n.s. & & & \\
\hline Age (years) & 0.99 & $(0.98-1.00)$ & n.s. & & & \\
\hline
\end{tabular}

*Without frailty calculated because Cox proportional hazard did not converge.

Abbreviations: HR: hazard ratio; Cl: Confidence interval; n.s. : not significant.

better for patients who had received radiotherapy ( $\mathrm{p}<$ 0.001) (Fig. 2).

\section{Survival analysis - Prognostic factors}

The univariate analysis of possible prognostic factors revealed a significantly lower risk of recurrence related to the following factors: additional irradiation, a fraction size of $\geq 2$ Gy with a hazard rate of $60 \%$, a total dose $>50$ Gy with a hazard rate of $59 \%(\mathrm{p}=0.028$, Table 4$)$. In multivariate analysis radiotherapy treatment and tumour localization in the abdominal wall were independent positive prognostic factors (Table 4). The comparison of adjuvant post-operative radiotherapy versus radiotherapy at recurrence found adjuvant radiotherapy to be significantly better $(p<0.001)$. Age was not a prognosticator. A more advanced age does not reduce the risk for a desmoid tumour. No age relation was found.

\section{Discussion}

The optimal treatment for patients with aggressive fibromatosis remains unclear. Desmoid tumours are slowly proliferating tumours. The ultimate treatment goal is tumour control as the probability of dying from aggressive fibromatosis is relatively low. Patients with an intraabdominal desmoid tumour are at a higher risk of dying of local tumour progression or of side-effects due to surgical or combined treatment. To achieve local control may be a challenge in these patients. Many have a local recurrence, often multiple recurrences, within the site of the primary tumour. Recurrence rates may differ with time and treatment modalities used. This makes it difficult to evaluate the value of adjuvant treatment, as radiotherapy could, for example, be given post-operatively or after a recurrence. The same patient could have had several resections and radiotherapy at some point in time. For this reason we have performed, in addition to the classic actuarial analysis (with the last follow-up as endpoint) a Cox Hazard Frailty Analysis. The classic analysis does not take into account a possible tumour and patient related risk, where some tumours keep recurring after the same primary treatment, whereas the Hazard Frailty Analysis takes into account the time-related probability of occurrence of failure and considers as such each patient individually.

\section{Surgery}

Wide surgical excision is considered to be the standard treatment and can result in a cure. Cure is defined as no tumour progression or relapse. Published data indicate that the likelihood of local recurrence after surgery alone is high with reported recurrence rates ranging from $20 \%$ to $90 \%[3,14-20]$. The local recurrence rate of $32 \%$ observed in this study was therefore low. Recurrence rates of up to $68 \%$ after resection have been described if positive resection margins are present $[9,16,19]$; whereas a local control of $85 \%$ in the case of a R0 excision can be reached [21]. In contrast, to what has been observed in this study, Reitamo et al found a lower recurrence rate after incomplete resection (17\%) compared to a wide excision (24\%) [2]. In an analysis of surgical margins between wide and microscopic complete resection we found only small differences. The reasons for these conflicting results are presumably due to: a selection bias in favour of the surgery alone group (in the survival analysis the recurrence rate is significantly lower for irradiated 


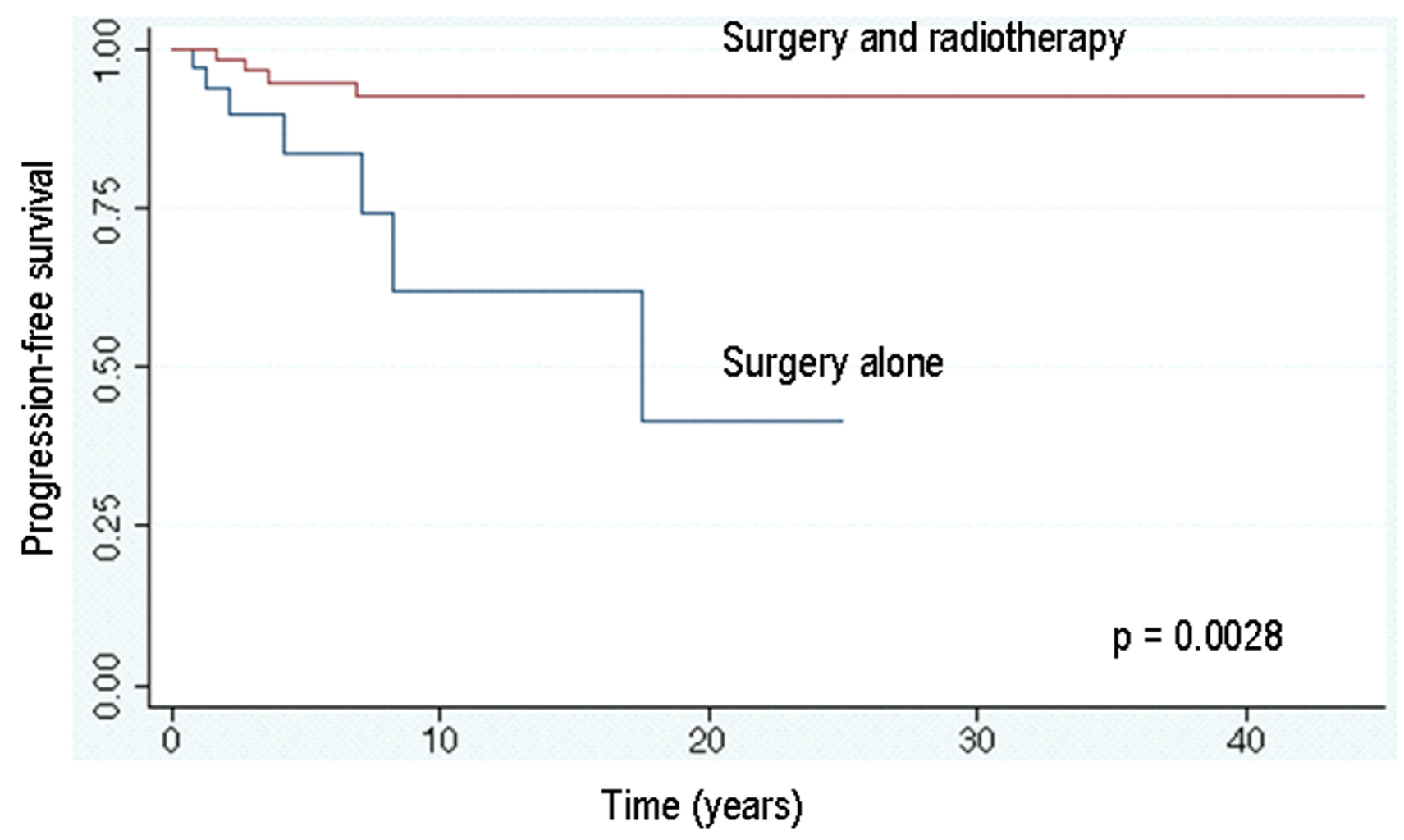

\begin{tabular}{|c|c|c|c|c|c|c|c|c|}
\hline & Years & 0 & 1 & 2 & 3 & 5 & 10 & 25 \\
\hline $\begin{array}{l}\text { Surgery and } \\
\text { radiotherapy }\end{array}$ & $\begin{array}{l}\text { Patients } \\
\text { at risk }\end{array}$ & 68 & 66 & 61 & 55 & 47 & 22 & 3 \\
\hline $\begin{array}{l}\text { Surgery } \\
\text { alone }\end{array}$ & & 38 & 34 & 22 & 19 & 13 & 4 & - \\
\hline
\end{tabular}

\section{Figure I}

Overall progression-free survival at the last reported follow-up (Kaplan-Meier curves).

patients); the retrospective nature of the evaluation (based mainly on the surgeon's description of radicality) and the fact that mainly Radiation Oncology departments participated in this study. As a result, many patients with no recurrence after radical resection were not included in the study.

\section{Radiotherapy}

Radiotherapy is a viable treatment option for desmoid tumours. This was shown as early as 1928 by J. Ewing [22]. Our data for local control after radiotherapy (75\%) lie near the higher range of published data (69-80\%) $[9,10,18,21,23-27]$. Local control is, independent of tumour status (primary or recurrent) and resection margin (negative versus positive), significantly increased if radiotherapy is added $[11,28]$. Post-operative adjuvant radiotherapy was significantly better than radiotherapy at recurrence. Recurrences reported after radiotherapy occurred within the field in 54\% of the cases, and at the field border in 30\%, out of the field in $16 \%$ and in areas irradiated with doses less than $50 \mathrm{~Gy}$ in $72 \%$ of the cases $[11,29,30]$. In this analysis, $61 \%(11 / 18)$ of the recurrences after irradiation were seen at the field border or in areas receiving doses less than $50 \mathrm{~Gy}$. We therefore support the recommendation of other investigators to add wide radiation field margins of at least $5 \mathrm{~cm}$ in the direction of possible infiltrative growth $[10,27]$.

To date there is insufficient published evidence to support a dose related effect. Recurrences after radiotherapy have 


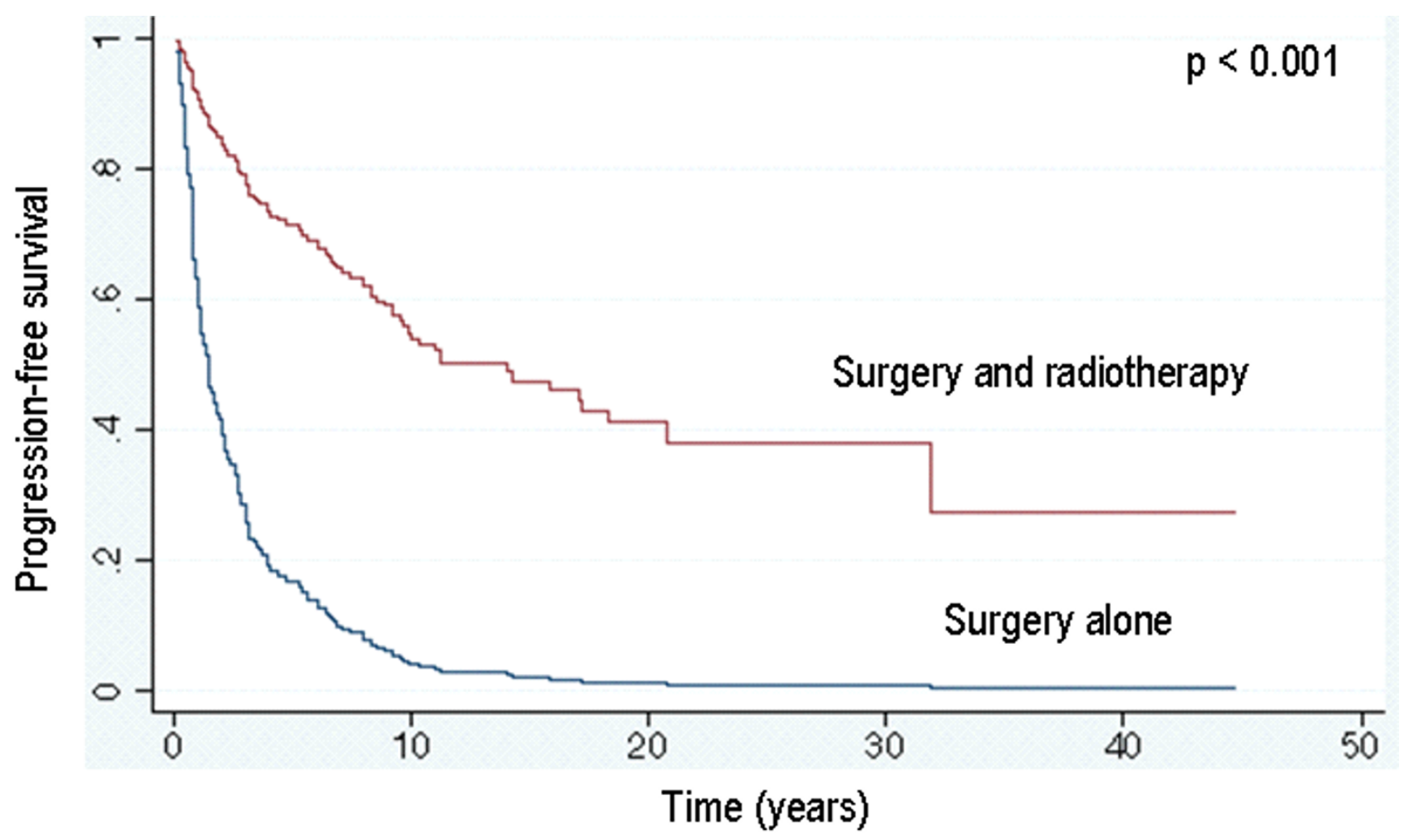

Figure 2

Progression-free survival taking multiple recurrent events per patient into account (Cox proportional hazard regression with shared frailty).

been reported with doses $>60$ Gy [9,31]. Although some investigators [32] could not demonstrate an improved tumour control rate for doses exceeding $50 \mathrm{~Gy}$, we and others have found a significantly better local control for doses > 50 Gy $(p=0.028)[8,33]$.

\section{Follow-up}

Most recurrences occur within 5 years [8-10,23,29]. Other workers are of the opinion that an earlier endpoint for evaluation is acceptable as $80 \%$ of all recurrences appear within the first two years of treatment $[17,19,20,33,34]$. In this study, 59\% of all recurrences appeared during the first 2 years and $82 \%$ during the 5 years following treatment. We detected recurrences at up to 20 years. For this reason and to our knowledge, this study has the longest reported range of follow-up ( 44 years) we would suggest that a longer mean follow-up than 5 years is advisable.

\section{Toxicity}

Side effects reported in this study were not complete. No difference between side effects after surgery and after radiotherapy could be demonstrated. For this reason, after a median follow-up of 6 years, no secondary malignant tumours after radiotherapy have been reported, which may be expected in such a population treated at a young age. However, this may still be observed after a longer mean follow-up.

\section{Pharmacologic agents}

Several systemic therapies have been proposed for the treatment of desmoid tumours. Responses to anti-estrogens [35-37], to non-steroidal and steroidal anti-inflammatories, and to cytotoxic chemotherapeutics have been reported [38-41]. Only one out of 10 patients (10\%) in this study treated with Tamoxifen showed a tumour response.

\section{Prognostic factors}

None of the prognostic factors such as gender, pregnancy or Gardner's syndrome described in the literature $[2,7,24]$ could be confirmed. Furthermore, we found no prognostic influence of age, whereas tumour localization was found to be a significant prognostic factor. A significant difference between trunk and extremities has been reported, with localization in the trunk having a better prognosis $[10,15,28]$. Tumours of the abdominal wall 
compared with tumours of the extremities showed a significantly better prognosis both in the univariate and multivariate analysis. A possible reason for this result is the better resectability of tumours in the abdominal wall. Anatomic structures are the limiting factors in extremities. However, an analysis of the surgical margins in these two regions did not support this hypothesis (data not shown). Another explanation could be the uneven distribution of patients with a tumour in the abdominal wall in the two treatment groups: the percentage of patients treated by surgery alone being higher. This finding is partly due to the fact that wide excision is the recommended first treatment approach. Patients are often referred to Radiation Oncology centres for treatment only after they had experienced multiple recurrences. Our data reflect this by the significantly higher number of re-operations found in the radiotherapy group. Last but not least, tumours of the abdominal wall may represent a different biologic behaviour. A first hint of this has been reported for Familial Adenomatous Polyposis (FAP) related desmoid tumours. Abdominal desmoids comprised the majority of FAP desmoids and extra-abdominal desmoids comprised the majority of non-FAP desmoids $(\mathrm{P}<0.001)$ [42]. FAP desmoids may be genetically different. Based on our data, however, we could show no final proof for the factors of resectability or aetiology as a reason for favourable outcome in patients with a desmoid tumour of the abdominal wall.

Additionally, adjuvant postoperative radiotherapy was a positive prognosticator for PFS if compared to radiotherapy at recurrence. The addition of radiotherapy at an earlier time point of the disease may be advisable. We looked at the fraction size under the hypothesis that as desmoid tumours are slow growing tumours originating from fibroblasts, and thus may need a higher single fraction size. The use of daily fractions $\geq 2$ Gy reduced the hazard for a tumour recurrence to $60 \%$. To our knowledge this finding concerning the fraction size for radiotherapy of aggressive fibromatosis has not been reported in the literature.

\section{Conclusion}

Wide resection remains the primary therapy, but, as this study shows, in certain situations adjuvant post-operative radiotherapy is a must in the treatment of aggressive fibromatoses. Radiotherapy should be part of the treatment concept for patients with non-radical tumour resection after primary surgery or at first recurrence, as well as for limb preservation. Radiotherapy should be considered early in the treatment concept because adjuvant postoperative radiotherapy improves local tumour control. The total dose applied should be above 50 Gy. Our data might indicate that it could be beneficiary to use fraction sizes $\geq 2$ Gy. The radicality and the number of re-opera- tions may be modified: adjuvant radiotherapy seems to compensate for positive resection margins and could therefore reduce the recurrence rate and avoid mutilating operations in this predominantly young patient group. However, the risk of a radiation induced tumour should be considered when treating young patients. A "cost-risk" estimation, whether the cost of a loss of a limb or more (e.g. as in a hemi-pelvectomy) versus the risk of a malignant tumour should be taken into account for each individual treatment decision.

Although it would be difficult to realize because of the rarity of these tumours, the contribution of radiotherapy to the treatment of desmoid tumours can only be answered by a prospective randomised clinical trial in a defined patient group, especially as modern three-dimensional radiotherapy treatment planning and the use of functional imaging may give a better indication of the incidence of recurrences and side effects.

\section{Competing interests}

The author(s) declare that they have no competing interests.

\section{Authors' contributions}

BGB: Designed and conducted the study, conducted data evaluation, wrote the article

MOS: Collected data, updated the follow-up, built the database, wrote first outline of the manuscript

AvH: Reviewed the pathology of all patients = reference pathologist.

SB: Support with data collection, entry of patients, critical review of the manuscript.

CL: Support with data collection, entry of patients.

KF: Support with pathological review of a subgroup of patients.

SV: Data collection, entry of patients, critical review of the manuscript.

MJK: Data collection, entry of patients, critical review of the study design and questionnaires.

GS: Data collection, entry of patients, critical review of the manuscript.

PT: Data collection, entry of patients, critical review of the manuscript. 
HKS: Data collection, entry of patients, critical review of the manuscript.

NL: Support with data collection, entry of patients.

RM: Support with data collection and pathology review.

GR: Data collection, entry of patients, critical review of the manuscript.

EAB: Data collection, entry of patients.

AW: Data collection, entry of patients

JA: Support with data collection.

UB: entry of patients.

HB: entry of patients.

UML: Participated in the design of the study, supported first statistical evaluation and data collection (building of the database).

JBD: Recalculated all radiotherapy doses into actual used doses according to ICRU. Critical review of the manuscript.

BS: Performed the statistical analysis, helped with drafting of the manuscript.

MI: Support with data collection for the surgical aspects of the study, critical review of the manuscript.

All authors read and approved the final manuscript

\section{Acknowledgements}

The authors thank Professor Philippe Lambin, MAASTRO (Maastricht Radiation Oncology), Maastricht, The Netherlands, for useful discussions.

\section{References}

I. Reitamo JJ, Häyry P, Nykyri E, Saxen E: The desmoid tumour. I. Incidence, sex-, age-, and anatomical distribution in the Finnish population. Am J Clin Pathol 1982, 77:665-673.

2. Reitamo JJ, Scheinin TM, Häyry P: The desmoid syndrome. New aspects in the cause, pathogenesis and treatment of the desmoid tumour. Am J Surg 1986, I5 I:230-237.

3. Plukker JT, van Oort I, Vermey A, Molenaar I, Hoekstra HJ, Panders AK, Dolsma WV, Koops HS: Aggressive fibromatosis (nonfamilial desmoid tumour): therapeutic problems and the role of adjuvant radiotherapy. Brit J Surg 1995, 82:5 |0-5|4.

4. Weiss SW, Goldblum JR: Fibromatoses. In Soft Tissue Tumours 4th edition. Edited by: Enzinger, Weiss. St. Louis, Mosby; 200I:309-346.

5. Gardner EJ, Richards RC: Multiple cutaneous and subcutaneous lesions occurring simultaneously with hereditary polyposis and osteomatosis. Am J Hum Genet 1953, 5:139-| 47.

6. Cheon SS, Cheah AY, Turley S, Nadesan P, Poon R, Clevers H, Alman BA: Beta-Catenin stabilization dysregulates mesenchymal cell proliferation, motility, and invasiveness and causes aggressive fibromatosis and hyperplastic cutaneous wounds. Proc Natl Acad Sci USA 2002, 99:6973-8.
7. Fletcher CDM: Soft Tissue Tumours. In Diagnostic Histopathology of Tumours London: Churchill Livingstone; 2000: 1497-I500.

8. Ballo MT, Zagars GK, Pollack A: Radiation therapy in the management of desmoid tumours. Int J Radiat Biol Phys 1998, 42: $1007-10 \mid 4$.

9. Spear MA, Jennings LC, Mankin HJ, Spiro IJ, Springfield DS, Gebhardt $M C$, Rosenberg AE, Efird JT, Suit HD: Individualizing management of aggressive fibromatoses. Int J Radiat Oncol Biol Phys 1998, 40:637-645.

10. Ballo MT, Zagars GK, Pollack A, Pisters PW, Pollack RA: Desmoid tumour: Prognostic factors and outcome after surgery, radiation therapy, or combined surgery and radiation therapy. J Clin Oncol 1999, I7:158-167.

II. Nuyttens J], Rust PF, Thomas ChR, Turrisi AT 3rd: Surgery versus radiation therapy for patients with aggressive fibromatosis or desmoid tumours. Cancer 2000, 88:1517-1523.

12. Rare Cancer Network [http://www.rarecancer.net]

13. ICRU Report 50: Prescribing, recording and reporting photon beam therapy. In International Commission on radiation units and measurements Bethesda, Maryland; 1993.

14. Easter DW, Halasz NA: Recent trends in the management of desmoid tumours. Summary of 19 cases and review of the literature. Ann Surg 1989, 2 1 0:765-769.

15. Higaki S, Tateishi A, Ohno T, Abe S, Ogawa K, lijima T, Kojima T: Surgical treatment of extra-abdominal desmoid tumours (aggressive fibromatoses). Int Orthop 1995, 19:383-389.

16. Lopez R, Kemalyan N, Moseley HS, Dennis D, Netto RM: Problems in diagnosis and management of desmoid tumours. Am J Surg 1990, I 59:450-453.

17. Markhede G, Lundgren L, Bjurstam N, Berlin O, Stener B: Extraabdominal desmoid tumours. Acta Orthop Scand 1986, 57:I-7.

18. Mendenhall WM, Zlotecki A, Morris CG, Hochwald SN, Scarborough MT: Aggressive fibromatosis. Am J Clin Oncol 2005, 28:2 II-2I5.

19. Posner MC, Shiu MH, Newsome JL, Haijdu S], Gayner J], Brennan MF: The desmoid tumour. Not a benign disease. Arch Surg 1989, 124:19|-196.

20. Rock MG, Pritchard DJ, Reimann HM, Soule EH, Brewster RC: Extra-abdominal desmoid tumours. J Bone Joint Surg Am 1984, 66:1369-1374.

21. Goy BW, Lee SP, Eilber F, Dorey F, Eckardt J, Fu YS, Juillard GJ, Selch MT: The role of adjuvant radiotherapy in the treatment of resectable desmoid tumours. Int J Radiat Oncol Biol Phys 1997, 39:659-665.

22. Ewing JE: Neoplastic Diseases. WB Saunders Co. Philadelphia; 1928.

23. Catton CN, O'Sullivan B, Bell R, Cummings B, Fornasier V, Panzarella T: Aggressive fibromatosis: optimisation of local management with a retrospective failure analysis. Radiother Oncol 1995, 34:17-22.

24. Karakousis CP, Mayordomo J, Zografos GC, Driscoll DL: Desmoid tumours of the trunk and extremity. Cancer 1993, 72:1637-164I.

25. Leibel SA, Wara WM, Hill DR, Bovill EG Jr, de Lorimier AA, Beckstead JH, Phillips TL: Desmoid tumours: local control and patterns of relapse following radiation therapy. Int J Radiat Oncol Biol Phys 1983, 9: I 167-I171.

26. Schulz-Ertner D, Zierhut D, Mende U, Harms W, Branitzki P, Wannenmacher $M$ : The role of radiation therapy in the management of desmoid tumours. Strahlenther Onkol 2002, 178:78-83.

27. Zelefsky MJ, Harrison LB, Shiu MH, Armstrong JG, Hajdu ST, Brennan MF: Combined surgical resection and Iridium 192 implantation for locally advanced and recurrent desmoid tumours. Cancer 1991, 67:380-384.

28. Kirschner MJ, Sauer R: Die Rolle der Radiotherapie bei der Behandlung von Desmoidtumouren. Strahlenther Onkol 1993, 169:77-82.

29. McCollough WM, Parsons JT, Van Der Griend R, Enneking WF, Heare T: Radiation therapy for aggressive fibromatosis. The experience at the University of Florida. J Bone Joint Surg 1991, 73:717-725.

30. Stockdale AD, Cassoni AM, Coe MA, Phillips RH, Newton KA, Westbury $\mathrm{G}$, Mackenzie DH: Radiotherapy and conservative surgery in the management of musculo-aponeurotic fibromatosis. Int J Radiat Oncol Biol Phys 1988, 15:851-857. 
31. Sherman NE, Romsdahl M, Evans H, Oswald MJ: Desmoid tumours: A 20 year radiotherapy experience. Int J Radiat Oncol Biol Phys 1990, 19:37-40.

32. Suit HD: Radiation dose and response of desmoid tumours. Int J Radiat Oncol Biol Phys 1990, 19:225-227.

33. Keus $R$, Bartelink $H$ : The role of radiotherapy in the treatment of desmoid tumours. Radiother Oncol 1986, 7:1-5.

34. McKinnon JG, Neifeld JP, Kay S, Parker GA, Foster WC, Lawrence W Jr: Management of desmoid tumours. Surg Gynecol Obstet 1989, 169:104-106.

35. Kinzbrunner B, Ritter S, Domingo J, Rosenthal CJ: Remission of rapidly growing desmoid tumours after tamoxifen therapy. Cancer 1983, 52:220I-2204.

36. Klein WA, Miller HH, Anderson M, DeCosse Jj: The use of indomethacin, sulindac, and tamoxifen for the treatment of desmoid tumours associated with familial polyposis. Cancer 1987, 60:2863-2868.

37. Procter $\mathrm{H}$, Singh L, Baum M, Brinkley D: Response of multicentric desmoid tumours to tamoxifen. $\mathrm{Br}$ J Surg 1987, 74:40I.

38. Brooks MD, Ebbs SR, Colletta AA, Baum M: Desmoid tumours treated with triphenylethylenes. Eur J Cancer 1992, 28: $1014-1018$.

39. Tsukada K, Church JM, Jagelman DG, Fazio VW, Lavery IC: Systemic cytotoxic chemotherapy and radiation therapy for desmoid in familial adenomatous polyposis. Dis Colon Rectum 1991, 34:822-826.

40. Umemoto S, Makuuchi H, Amemiya T, Yamaguchi H, Oka S, Owada $\mathrm{T}$, Koizumi K: Intra-abdominal desmoid tumours in familial polyposis coli: a case report of regression by prednisolone therapy. Dis Colon Rectum 1991, 34:89-93.

4I. Weiss AJ, Horowitz S, Lackman RD: Therapy of desmoid tumours and fibromatoses using vinorelbine. Am J Clin Oncol 1999, 22:193-5.

42. Fallen T, Wilson M, Morlan B, Lindor NM: Desmoid tumors - a characterization of patients seen at Mayo Clinic 1976-1999. Fam Cancer 2006, 5:191-4.

Publish with Bio Med Central and every scientist can read your work free of charge

"BioMed Central will be the most significant development for disseminating the results of biomedical research in our lifetime. "

Sir Paul Nurse, Cancer Research UK

Your research papers will be:

- available free of charge to the entire biomedical community

- peer reviewed and published immediately upon acceptance

- cited in PubMed and archived on PubMed Central

- yours - you keep the copyright 